\title{
PERFORMANCE ANALYSIS OF THERMAL DIODES
}

\author{
H. A. Machado ${ }^{a, b}$ \\ and A. G. Ramos ${ }^{c}$ \\ ${ }^{\mathrm{a}}$ Centro Técnico Aeroespacial \\ Instituto de Aeronáutica e Espaço \\ Pr. Mal. Eduardo Gome, 50, Vila das Acácias \\ 12228-904, São José dos Campos, SP, Brasil \\ humbertoam@iae.cta.br

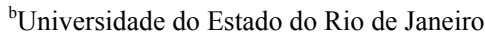 \\ Faculdade de Tecnologia \\ Estrada Resende-Riachuelo, s/n \\ 27523-000, Resende, RJ, Brasil \\ machado@fat.uerj.br \\ ${ }^{c}$ Universidade do Vale do Paraíba \\ Instituto de Pesquisa e Desenvolvimento \\ Av. Shishima Hifume, 2911, Urbanova \\ 12244-000, São José dos Campos, SP, Brasil
}

\section{ABSTRACT}

The thermal diode consists in a common brick empty inside, where the internal cavity is geometrically arranged as two rectangles, disposed one over the other but not aligned. When the lower side is heated, natural convection in the air inside yields high heat transfer rates from this side to the other. When the upper side is heated, the heat transfer should run by pure conduction, and the brick with air inside works as a thermal insulator. As this brick allows a good conductance in one direction and insulation in the opposite sense, it behaves as an electric diode, being known as thermal diode. This principle is already known for a long time, but its use is still not extensive, and there are no basic rules for the cavity design or even a theoretical study of viability for this use replacing the conventional insulation systems. The objective of this work is to simulate the heat transfer process inside a thermal diode, in order to obtain the optimal geometry and dimensions and to verify the viability of its use in buildings for thermal optimization. The numerical data are validated through comparing with that obtained from the test applied to cellular concrete bricks.

Keywords: Thermal diode, Insulation, Thermal comfort, Natural convection

\section{NOMENCLATURE}

A brick height, $\mathrm{m}$

$\mathrm{C}_{\mathrm{p}} \quad$ specific heat at constant pressure, $\mathrm{J} /(\mathrm{kg} . \mathrm{K})$

$\mathrm{d}$ brick minor thickness, $\mathrm{m}$

e brick major thickness, $m$

$\mathrm{H}$ heat function, $\mathrm{W} / \mathrm{m}^{2}$

I indicator function, dimensionless

$\mathrm{k}$ thermal conductivity, W/m.K

$\mathrm{L}$ brick transversal length, $\mathrm{m}$

$\mathrm{P}$ pressure, $\mathrm{Pa}$

Pr Prandtl number

Ra Rayleigh number

$\mathrm{t}$ time, $\mathrm{s}$

$\mathrm{T}$ temperature, $\mathrm{K}$ or ${ }^{\circ} \mathrm{C}$

u velocity vector, $\mathrm{m}$

w mass flux vector, $\mathrm{kg} / \mathrm{m}^{2} . \mathrm{s}$

\section{Greek symbols}

$\rho \quad$ density, $\mathrm{kg} / \mathrm{m}^{3}$

$\mu \quad$ viscosity, Pa.s

\section{INTRODUCTION}

Thermal control of rooms and buildings has being deserved more attention of designers and architects, specially in the new generation buildings, the so called intelligent buildings, where the internal conditions and rational use of energy for acclimatization and maintenance costs are taken into account. During the project stage, the indoor desired conditions have to be reached with minor costs and environment impact (Mascaró and Mascaró, 1999). As a consequence, some alternatives to the conventional systems for thermal insulation in buildings (use of thermal insulation materials and double walls) have appeared. Such alternatives include the natural acclimatization and the use of configurations that allow a better circulation and ventilation, improving the heat exchange inside the building (Torreira, 1980, Mascaró and Mascaró, 1999).

An alternative to the conventional thermal insulation methods is the use of the thermal diode, which consists in a common brick empty inside, where the internal cavity is geometrically arranged as two rectangles, disposed one over the other but not aligned, Fig. (1).

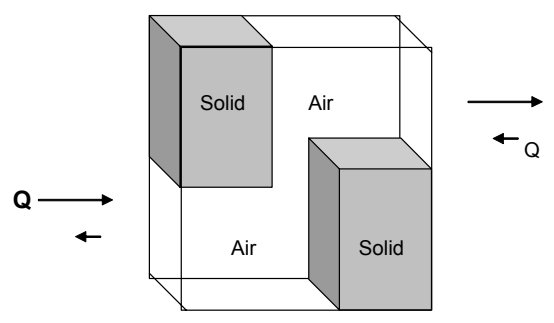

Figure 1. Three-dimensional view of a thermal diode.

When the lower side is heated, Fig. (2.a), natural convection in the air inside yields high heat transfer rates from this side to the other. When the upper side is heated, Fig. (2.b), the heat transfer runs by pure conduction, and the brick with air inside works as a 
thermal insulator, due air's low thermal conductivity, when compared to the solid materials commonly used in bricks (Özisik, 1990). As this brick allows a good conductance in one direction and insulation in the opposite side, it behaves as an electric diode, being known as thermal diode. Since it is basically a common brick, the cost increment for its manufacturing is very small.

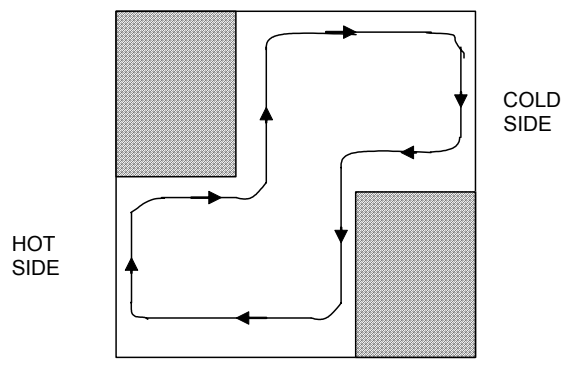

(a) Natural convection

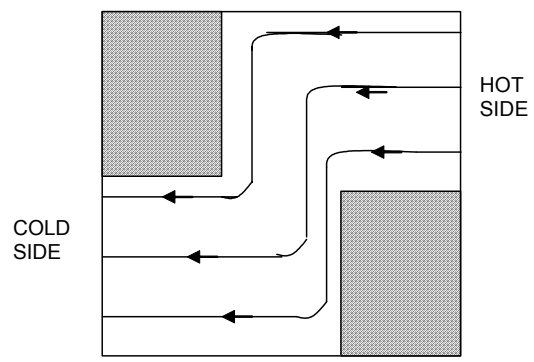

(b) Conduction only

Figure 2. Heat exchange in a thermal diode.

Thermal diode use is especially recommended in situations where the weather presents high thermal amplitude, and room's temperature should not vary strongly, as in electronic equipments, CPDs, high precision laboratories and others (Mascaró and Mascaró, 1999).

This principle is already known for a long time, but its use is still not extensive, and there are no basic rules for the cavity design or even a theoretical study of viability for this use replacing the conventional insulation systems (Özisik, 1990, Mascaró and Mascaró, 1999). Barata et al. (1988) have simulated the effect of inclination and internal shape of the cavity in the heat exchange, studying the Nusselt number amplification through both parameters, and keeping a unitary aspect ratio. The optimal shape found is similar to that proposed in the current work, and was called Cavidade Retificadora ("Fitting Cavity") by the authors.

The objective of this work is to simulate the heat transfer process inside a thermal diode, in order to obtain the optimal geometry and dimensions, and to verify the viability of its use in buildings when compared to the traditional insulators. The numerical data are validated through comparing with that obtained from the test of some configurations applied to cellular concrete bricks.

\section{PHYSICAL PROBLEM AND MATHEMATICAL MODEL}

The two-dimensional transient Navier-Stokes and energy equations and mass conservation equation were employed to simulate the process of heat exchange inside the cavity. The fluid was considered Newtonian, with constant density, except in the body force term (Boussinesq hypothesis), what is usual in this kind of problem:

$$
\begin{gathered}
\nabla \cdot \mathbf{w}=0 \\
\frac{\partial(\mathbf{w})}{\partial \mathrm{t}}+\nabla \cdot(\mathbf{w u})=-\nabla \mathrm{P}+\operatorname{Pr} \nabla \cdot(\mu \cdot \nabla \mathbf{u})+\operatorname{Pr} \cdot \operatorname{Ra} \cdot \mathrm{T} \\
\frac{\partial\left(\rho_{\mathrm{p}} \mathrm{T}\right)}{\partial \mathrm{t}}+\nabla \cdot\left(\mathbf{w C}_{\mathrm{p}} \mathrm{T}\right)=\nabla(\mathrm{k} \cdot \nabla \mathrm{T})
\end{gathered}
$$

where $\mathbf{u}$ is the velocity, $\rho$ is the density, $\mathbf{w}=\rho \mathbf{u}$ (mass flux), $\mathrm{t}$ is the time, $\mathrm{P}$ is the pressure, $\mathrm{T}$ is the temperature, $\mu$ is the viscosity, $\operatorname{Pr}$ is the Prandtl number, $\mathrm{Ra}$ is the Rayleigh number, $\mathrm{C}_{\mathrm{p}}$ is the specific heat and $\mathrm{k}$ is the thermal conductivity. Terms in bold are vector quantities, and dimensionless properties are relative to its values at mean temperature.

The materials (brick or air) were defined by its values for the indicator function, $\mathrm{I}(\mathbf{x})$, equal to 1 for the air and 0 for the concrete. Although being considered constants, the properties of each phase are different. A property $\phi\left(\rho, \mu, \mathrm{C}_{\mathrm{p}}\right.$ or $\left.\mathrm{k}\right)$ is calculated by:

$$
\phi(\mathbf{x})=\phi_{\text {solid }}+\left(\phi_{\text {air }}-\phi_{\text {solid }}\right) \mathrm{I}(\mathbf{x})
$$

The Heat Function $(\mathrm{H})$ is a useful tool that allows visualizing the heat exchange way between the walls, and was defined as (Polina et al., 1989):

$$
\begin{aligned}
& \mathrm{H}_{\mathrm{y}}=\rho \cdot \mathrm{C}_{\mathrm{p}} \cdot \mathrm{u} \cdot \mathrm{T}-\mathrm{k} \cdot \mathrm{T}_{\mathrm{x}} \\
& \mathrm{H}_{\mathrm{x}}=-\rho \cdot \mathrm{C}_{\mathrm{p}} \cdot \mathrm{v} \cdot \mathrm{T}+\mathrm{k} \cdot \mathrm{T}_{\mathrm{y}}
\end{aligned}
$$

Operation conditions considered were that commonly found in buildings, extended to regions with high thermal amplitude (Mascaró and Mascaró and Mascaró and Mascaró, 1999). The model was built considering variable air and concrete properties, although under the operation range, property variation can be neglected (Zhong et al., 1985).

\section{RESULTS AND DISCUSSION}

The computational code was built in FORTRAN, and the Finite Volume method was employed to solve the system of equations (Patankar, 1980). The PRIME algorithm was used for pressure-velocity coupling (Maliska, 1995). 
The numerical procedure was validated comparing with the benchmark results for the classic problem of the square cavity heated at different temperatures, obtained from the Generalized Integral Transform Technique - GITT (Machado et al., 2000). Results for $\mathrm{Ra}=10^{4}$ show more than $1 \%$ of accuracy.

\section{Determination of optimal dimensions}

First the problem was treated as a pure convection process, neglecting the heat conduction in the cavity walls, so as to verify the system behavior. Cases were ran considering dimensions of a feasible brick and the properties of the concrete and air at 300 K, Tab. (1), with vertical walls at constant temperature and horizontal walls at zero heat flux (thermally insulated). Due the high processing time, the results were obtained for a maximum Rayleigh number of 3000 (that corresponds to a temperature difference of $0.01^{\circ} \mathrm{C}$ ). Such cases were used to determine the optimal cavity dimensions, Fig. (3).

Table 1. Physical properties of air $(300 \mathrm{~K})$ and concrete brick.

\begin{tabular}{|c|c|c|}
\hline \multirow{4}{*}{$\begin{array}{l}\text { Concrete brick } \\
\text { (Sical, 2001) }\end{array}$} & Density & $\rho=500 \mathrm{~kg} / \mathrm{m}^{3}$ \\
\hline & $\begin{array}{l}\text { Thermal } \\
\text { conductivity }\end{array}$ & $\begin{array}{l}\mathrm{k}=0.1-0,2 \\
\mathrm{~W} / \mathrm{m}^{\circ} \mathrm{C}\end{array}$ \\
\hline & Specific heat & $\begin{array}{l}\mathrm{Cp}=800 \mathrm{~J} / \mathrm{kg} \\
{ }^{\circ} \mathrm{C}\end{array}$ \\
\hline & $\begin{array}{l}\text { Compression } \\
\text { strength }\end{array}$ & $2.5 \mathrm{Mpa}$ \\
\hline \multirow[t]{4}{*}{$\begin{array}{l}\text { Air (Özisik, } \\
1990)\end{array}$} & Density & $\begin{array}{l}\rho=1.1774 \\
\mathrm{~kg} / \mathrm{m}^{3}\end{array}$ \\
\hline & $\begin{array}{l}\text { Thermal } \\
\text { conductivity }\end{array}$ & $\begin{array}{l}\mathrm{k}=0.0262 \\
\mathrm{~W} / \mathrm{m}^{\circ} \mathrm{C}\end{array}$ \\
\hline & Specific heat & $\begin{array}{l}\mathrm{Cp}=1005.7 \\
\mathrm{~J} / \mathrm{kg}^{\circ} \mathrm{C}\end{array}$ \\
\hline & Viscosity & $\begin{array}{l}\mu=1.985 \mathrm{x} \\
10^{-5} \text { N.s }\end{array}$ \\
\hline
\end{tabular}

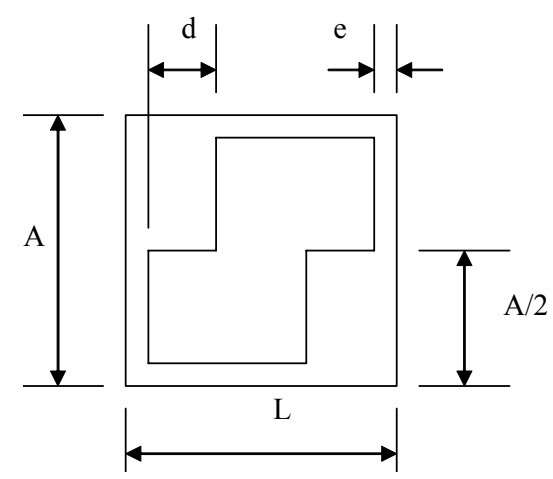

Figure 3. Cavity dimensions.

According to the numerical results, the thermal diode presents the predicted behavior only in cases where the solid thermal conductivity is quite smaller than the air conductivity. In this case, thermal resistance difference among the heat exchange direction tends to increase continuously with the ratio $\mathrm{d} / \mathrm{L}$. When the left wall temperature (Tw) is higher than the right wall temperature (Te), heat convection becomes stronger and thermal resistance decreases Fig. (4.a). Such situation has little practical interest, since solid materials commonly used (even thermal insulators) have thermal conductivity higher than air (Torreira, 1989).

When thermal conductivity of the solid is higher than the air's conductivity, as in the case of the brick with a cavity $\left(\mathrm{k}_{\text {solid }} / \mathrm{k}_{\text {air }}=5\right)$, the behavior observed was contrary to the expectative: if $\mathrm{Tw}$ is lower than Te, thermal resistance reduces, because the higher conductivity of the solid permits the cooling of the upper air layer and the heating of the downer air layer, increasing the convection intensity. In this case, the ratio $\mathrm{d} / \mathrm{L}$ that yields the highest difference of thermal resistance between the two directions for heat exchange is 0.3 - Fig. (4.b).

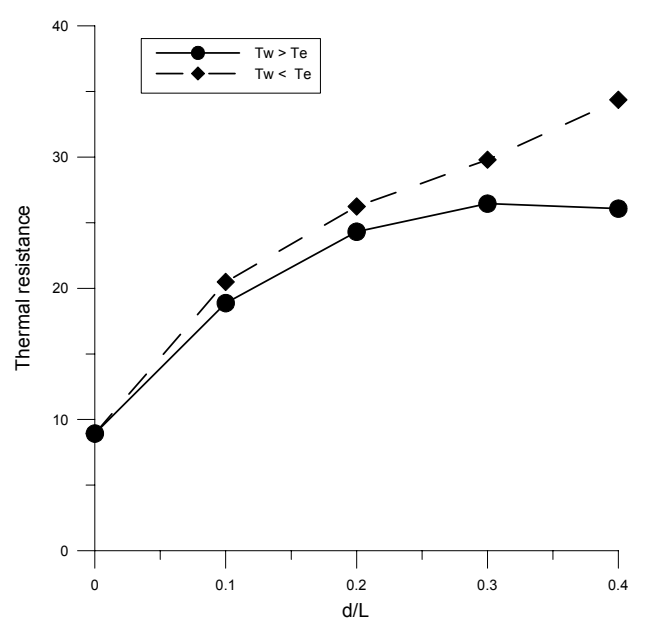

(a) $\mathrm{k}_{\text {solid }}<\mathrm{k}_{\text {air }}$

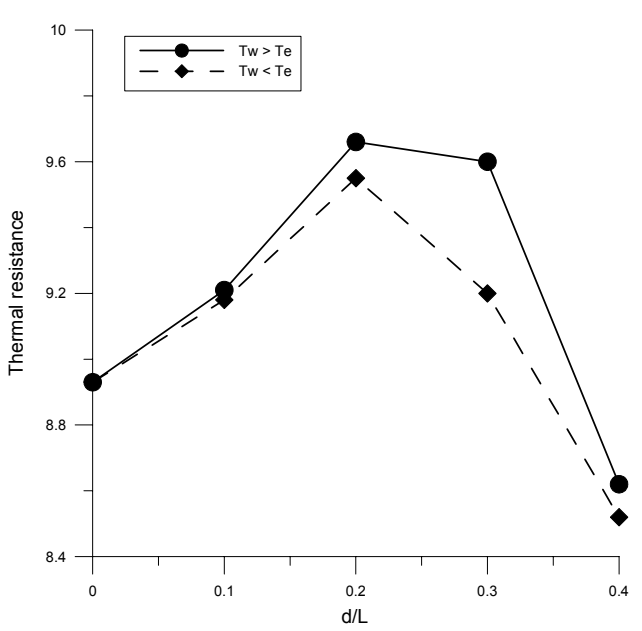

(b) $\mathrm{k}_{\text {solid }}>\mathrm{k}_{\text {air }}$

Figure 4. Variation of thermal resistance of the cavity with $\mathrm{d} / \mathrm{L}$.

The solution of the conjugated problem of convection inside the cavity and conduction in the 
walls considering $15 \mathrm{~mm}$ thickness for the brick walls (which was chosen taking into account the minimum compression resistance) is shown in Fig. (5). The presence of the wall reduces greatly the convection effects, what was not considered at the beginning of the work. The maximum difference of thermal resistance reaches $0.84 \%$, and the direction of it varies according to the ratio $\mathrm{d} / \mathrm{L}$.

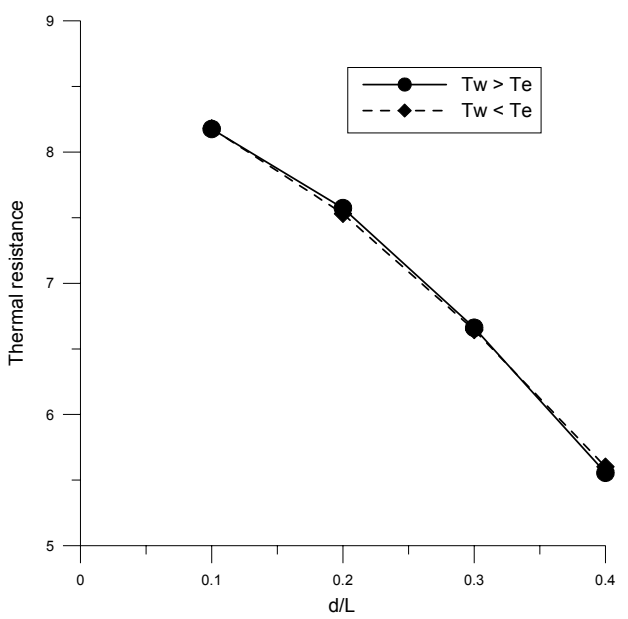

Figure 5. Variation of thermal resistance of the cavity with $\mathrm{d} / \mathrm{L}$ for conjugated problem.

In Figs. (6-8), one can observe the physical behavior of the heat exchange. In Fig. (6), isotherms show that the solid material stands with a small temperature difference, due its high thermal conductivity, what makes the air temperature in each cavity region get closer to the temperature of the thicker regions of the walls. In Fig. (7), streamlines show the recirculation caused by temperature difference. The basic difference among the flows in two cases is the direction of rotation. In Fig. (8), the heat lines (isolines of heat function) show that the influence of convection is stronger in the case where $\mathrm{Tw}>\mathrm{Te}$, that causes a bigger deformation in the way of energy between the walls.

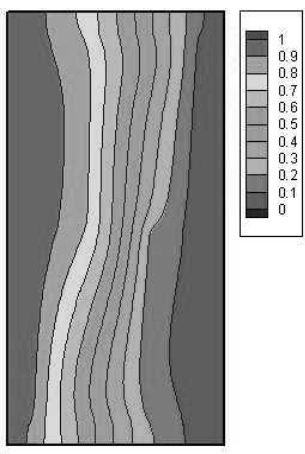

(a) $\mathrm{Tw}>\mathrm{Te}$

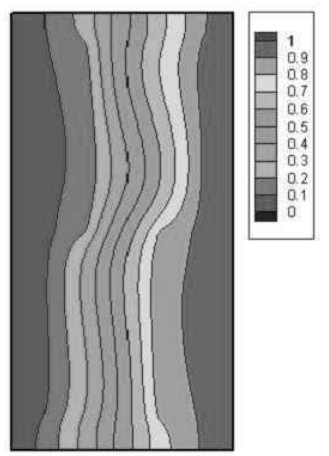

(b) $\mathrm{Tw}<\mathrm{Te}$
Figure 6. Isotherms for $\mathrm{d} / \mathrm{L}=0.3$ and $\mathrm{Ra}=3000$.

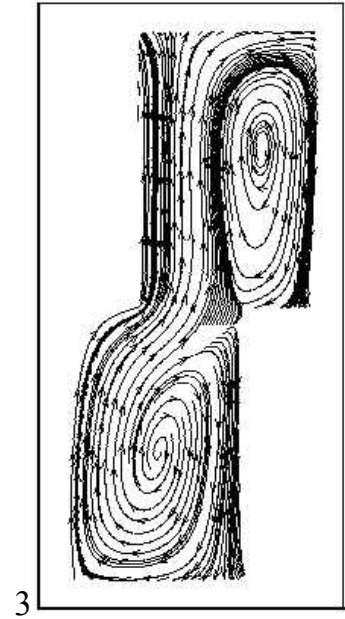

(a) $\mathrm{Tw}>\mathrm{Te}$

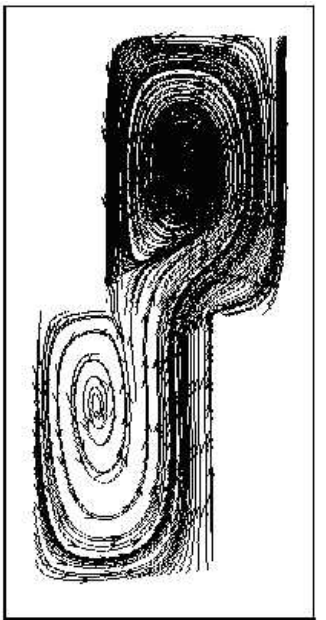

(b) $\mathrm{Tw}<\mathrm{Te}$
Figure 7. Streamlines for $\mathrm{d} / \mathrm{L}=0.3$ and $\mathrm{Ra}=$ 3000 .

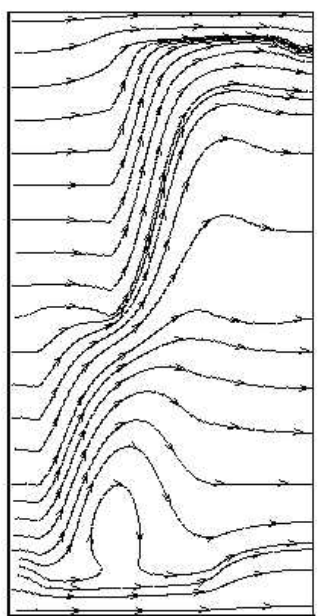

(a) $\mathrm{Tw}>\mathrm{Te}$

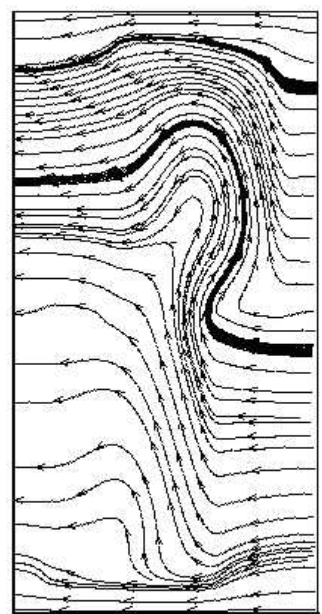

(b) $\mathrm{Tw}<\mathrm{Te}$
Figure 8. Heat lines for $\mathrm{d} / \mathrm{L}=0.3$ and $\mathrm{Ra}=3000$.

The simulation results, even if obtained for a low Rayleigh number, show a difference of thermal resistance, although when the effect of thickness is added to the problem, the direction of such variation is not evident.

As the most desirable characteristic for the brick is the highest difference among the thermal resistances, according to the heat transfer direction, the tests were done for the optimal configuration $(d / L$ $=0,3)$.

\section{Experimental results}

For high temperature differences, experimental tests were done. The set up schedule is shown in Figs. (9-10), and is similar to that proposed by Moura et al. (1993). The boundary conditions used were prescribed wall temperature in the cold side (mixture of ice and water at $0^{\circ} \mathrm{C}$ ) and prescribed heat flux in the hot side, produced through an electrical resistance 
put under a copper plate in straight contact with the brick's face and thermally insulated from the other surfaces. The heat flux was controlled with a c.c. electrical source and considered equal to the measured electrical power.

Initially, the set up was tested for the case of pure heat conduction, so as to calibrate the system and validate the physical model (including the physical properties used for the brick material). After steady state was established, the copper flat plate at the hot side reached $46^{\circ} \mathrm{C}$. The heating power was $10 \mathrm{~W}$. Supposing one-dimensional pure conduction in the brick the estimated thermal conductivity was 0.18 $\mathrm{W} / \mathrm{m}{ }^{\circ} \mathrm{C}$. This result agrees with the literature $(0.1-$ $0.2 \mathrm{~W} / \mathrm{m}{ }^{\circ} \mathrm{C}$, depending on the brick humidity Pietrobon et al., 2001; SICAL, 2001).

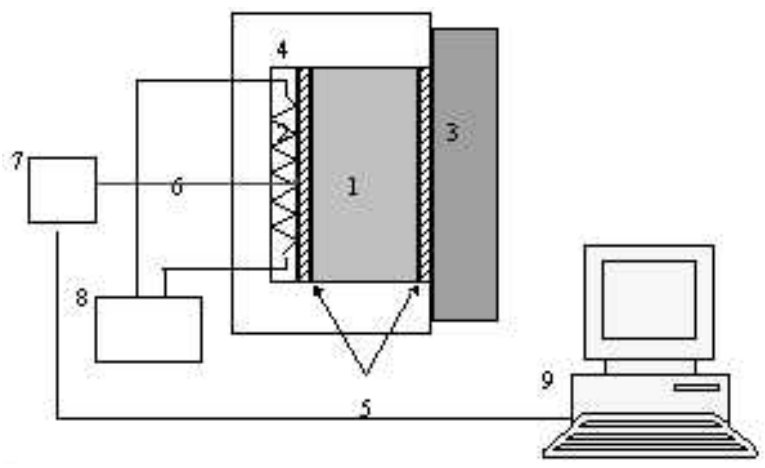

1. Concrete brick

2. Electrical resistance for heating

3. Water + ice

4. Thermal insulation

5. Copper flat plates

6. Thermocouples

7. Acquisition system

8. Heating power control

9. Computer

Figure 9. Experimental set up.

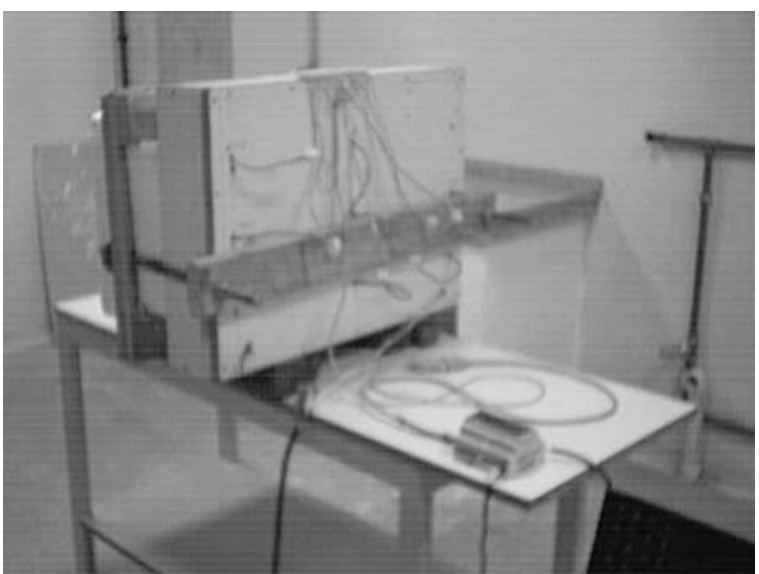

Figure 10. Set up view.

Once the set up was tested for pure conduction, the brick prototype (brick with a cavity) - Figs. (11-
12) was tested under similar conditions. The heating power was kept to $20 \mathrm{~W}$. Steady state was reached after 12 hours. The steady state results are shown in Tab. (2).

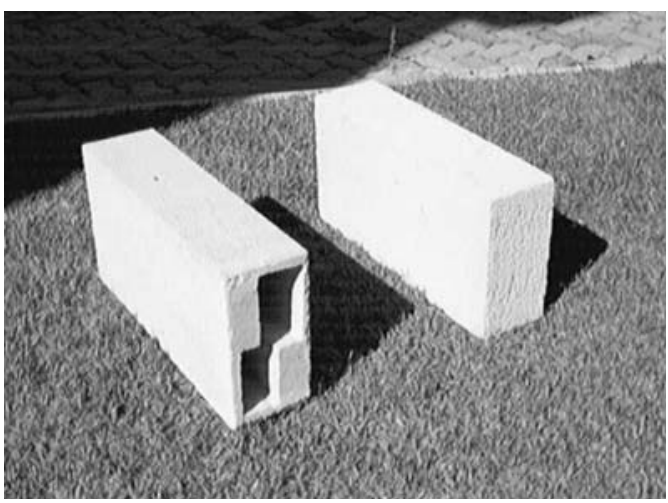

Figure 11. Prototype and original concrete brick.

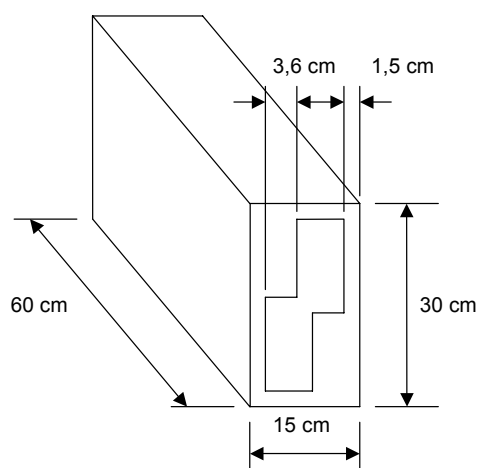

Figure 12. Prototype dimensions.

The result confirms what was observed in the simulation: a difference of thermal resistance according to the direction of heat transfer. The Rayleigh number estimated for the experience was $\mathrm{Ra}=10^{8}$, that indicates a strong turbulence inside the cavity, and consequently, high convective instabilities, what probably has influenced the heat exchange.

Table 2. Results for prototype test, after reached steady state.

\begin{tabular}{|c|c|c|}
\hline $\begin{array}{c}\text { Configuration } \\
\text { relative to Fig. } \\
(3)\end{array}$ & $\Delta \mathrm{T}$ & $\begin{array}{c}\text { Thermal } \\
\text { Resistance }\end{array}$ \\
\hline $\mathrm{Tw}>\mathrm{Te}$ & $39,4^{\circ} \mathrm{C}$ & $1,96^{\circ} \mathrm{C} / \mathrm{W}$ \\
\hline $\mathrm{Tw}<\mathrm{Te}$ & $41,1^{\circ} \mathrm{C}$ & $2,05^{\circ} \mathrm{C} / \mathrm{W}$ \\
\hline Variation & $4,3 \%$ & $4,3 \%$ \\
\hline
\end{tabular}

The empirical behavior of the thermal resistance confirms what was expected for the thermal diode. When Tw $>$ Te, the convection becomes more active, reducing the brick's thermal resistance. 


\section{CONCLUSIONS}

The solution of the physical problem with a computational code resulted in the validation of the mathematical model. Along with an experimental test, several data about the thermal behavior and transient response of the thermal diode were obtained. The main conclusion is that a feasible diode behaves as it was expected according to the physical model. Although the variation of thermal resistance according to the heat transfer direction was confirmed, its intensity does not indicate the viability of its use in thermal optimization of indoor environments. More tests with other dimensions and materials and an economic analysis are needed for a definitive conclusion.

\section{ACKNOWLEDGEMENTS}

Authors would like to thank to $\mathrm{CNPq}$ for the financial support during this work.

\section{REFERENCES}

Barata, J. M., Durão, D. F. G. and Reis, A. J. P. S., 1988, Convecção Natural em Cavidades, B.C.T. 11/12, pp 32-35, Lisboa.

Machado, H. A., Leal, M. A. and Cotta, R. M., 2000, Integral Transform Solutions of Transient Natural Convection in Enclosures with Variable Fluid Properties, International Journal of Heat \& Mass Transfer, Vol. 43, pp 3977-3990.

Maliska, R. C., 1995, Transferência de Calor e Mecânica dos Fluidos Computacional, LTC.

Mascaró and Mascaró, J. L. and Mascaró and Mascaró, L., 1999, Uso Racional de Energia em Edificações - Isolamento Térmico, Agência para Aplicação de Energia, São Paulo.

Moura, L. M., Lamberts, R., Philippi, P. C., Souza, R. V. C., 1993, Protótipo Nacional de um Equipamento para a Medição da Condutividade Térmica de Materiais de Construção, in: Second Brazilian Meeting on Comfort in the Built Environment, 139-144.

Özisik, M. N., 1990, Transferência de Calor, Guanabara Koogan.

Patankar, S. V., 1980, Numerical Heat Transfer and Fluid Flow, Hemisphere Publishing Corporation.

Pietrobon, C. L. R., Pietrobon, C. E., Alves, S. M., 2001, A Variação da Condutividade Térmica de Materiais de Construção Moldados In Loco com a Umidade e a Densidade: Experimentos Didáticos com Equipamentos Tecnologicamente Apropriados, www.cefetpr.br.

Polina, S., Silva, A. F. C. and Maliska, C. R., 1989, Considerações Sobre o Uso da Função Calor em Problemas de Convecção Natural em Cavidades, in: Anais do X ENCIT, pp. 269-272, Rio de Janeiro.

Sical, 2001, Catálogos atualizados, Belo Horizonte.
Torreira, R. P., 1980, Isolamento Térmico, Fulton Editora Técnica.

Zhong, Z. Y., Yang, K. T. and Lloyd, J. R., 1985, Variable Property Effects in Laminar Natural Convection in a Square Enclosure, Journal of Heat Transfer, Vol. 107, pp. 103-138.

Received: February 05, 2006

Revised: March 05, 2006

Accepted: April 05, 2006 